Send your letters to the editor, British Dental Journal, 64 Wimpole Street, London W1G 8YS E-mail bdj@bda.org

Priority will be given to letters less than 500 words long. Authors must sign the letter, which may be edited for reasons of space

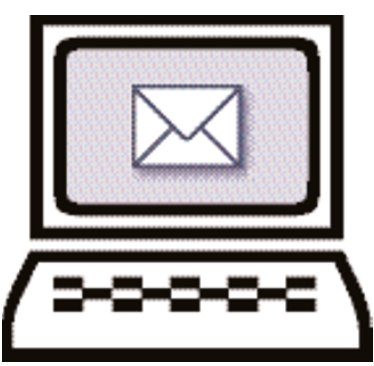

The authors say and I quote 'Replantation of primary incisors has been carried out in some studies...' and '...the majority of studies contraindicate replantation...' From these statements the readers may get the wrong impression that the authors' conclusions are based on hard evidence, but 'the literature is based on sporadic case reports rather than any scientific evaluation' as the authors correctly cite in the introduction.

I agree with the authors' opinion that if the dentist, due to parental pressure, is 'forced' to replant an avulsed primary incisor, endodontic treatment and longterm follow-up are crucial. The authors, as opponents of replantation of avulsed primary teeth, do not mention additional necessary steps required to decrease failure of the replantation and complications. Postoperative complications can be anticipated if replantation is not accompanied by the same additional supportive treatment mentioned for replanted permanent teeth, such as splint, strict oral hygiene, antibiotic therapy, and removal of the periodontal ligament if replantation is delayed.

The fact that the authors base their conclusion on outcomes of a single case, in which the treatment can be considered as malpractice, is more than disturbing.

As Al-Khayatt and Davidson state in their case report: '...the majority of articles and chapters in textbooks [NOT studies] contraindicate replantation, due to the high risk of complications to the developing permanent successor'. These, however, are opinions and not evidence-based conclusions. While, as aforementioned, the literature on replantation of primary teeth is based on sporadic case reports, there is not even one single anecdotal report attributing damage inflicted to the permanent tooth to replantation of its primary predecessor, all the more so, a controlled study in which avulsed primary teeth are randomly assigned to be replanted or given to the tooth fairy. ${ }^{2}$
Thirty-eight to $85 \%$ of permanent teeth presented developmental disturbances following avulsion of their primary predecessors, ${ }^{3-7}$ even when the primary teeth were not replanted. This, however, does not guarantee that the apex of the primary tooth does not inflict additional damage to the developing permanent tooth during insertion of the avulsed primary tooth back to its socket. A simple way to cope with this risk has been suggested in three different reports. ${ }^{8-10}$ The root of the avulsed primary teeth has been shortened by 2-3 $\mathrm{mm}$ prior to replantation. The significance of these cases lies in the positive attitude of the operators, who attempted to cope with the challenge by suggesting a creative technique rather than avoiding treatment and hiding behind guidelines.

\section{G. Holan}

Israel

1. Zamon E L, Kenny D J. Replantation of avulsed primary incisors: A risk-benefit assessment. J Can Dent Assoc 2001; 67: 386

2. Johnson R. Traumatic dental injuries in children Part 1: evaluation of traumatic dental injuries and treatment of injuries to primary teeth. Update in Pediatr Dent 2(3), July 1989.

3. Ravn J J. Sequelae of acute mechanical traumata in the primary dentition. J Dent Child 1968; 35: 281 289.

4. Andreasen J O, Ravn J J. The effect of traumatic injuries to primary teeth on their permanent successors. II. A clinical and radigraphic follow-up study of 213 teeth. Scand J Dent Res 1971; 79 : 284-294.

5. Ravn J J. Developmental disturbances in permanent teeth after exarticulation of their primary predecessors. Scand J Dent Res 1975; 83 131-134.

6. Brin I, Ben-Bassat Y, Fux A, Zilberman Y. Trauma to the primary incisors and its effect on the permanent successors. Pediatr Dent 1984; 6: 78 82.

7. von Arx T. Developmental disturbances of permanent teeth following trauma to the primary dentition. Austr Dent J 1993; 38: 1-10.

8. Šmelhaus S. Über die Replantation der Milchzähne. Z Stomatol 1925; 23: 52-57.

9. Kokich V G, Shapiro P A, Oswald R et al. Ankylosed teeth as abutments for maxillary protraction: $A$ case report. Am J Orthod 1985; 88: 303-307.

10. Filippi A, Pohl Yango, Kirschner H. Replantation of avulsed primary anterior teeth: Treatment and limitations. J Dent Child 1997; 64: 272-275. authors are somewhat tendentious. 
The authors A. S. Al-Khayatt and L. E. Davidson respond: We would like to thank G. Holan for his/her interest in the recent publication of our paper. The aim of this report was to increase the awareness of practitioners of the potential pitfalls of replanting primary incisors. $^{1}$

The literature reviewed identified publications in which the action of replanting primary incisors has been both favourable and unfavourable; however as explained, this is entirely based on sporadic reports and personal opinions rather than scientific evaluation. Indeed there exists very little scientific evidence on the long-term success of replantation of primary incisors ${ }^{2}$ and making assumptions based on 'a few successful reports' is not considered evidence-based dentistry. ${ }^{3,4}$

As regards guidelines, their purpose is to improve effectiveness and efficiency of clinical care through identification of good clinical practice and desired clinical outcomes. Inevitably there will be areas of practice where there is a shortage of reliable research data, so that while some recommendations are supported by robust data, others are made with a lesser degree of confidence and may represent only 'best current practice." ${ }^{4}$

The authors neither sought to hide behind such guidelines nor are necessarily opponents of replantation of primary incisors where appropriate case selection has been undertaken. In the emergency situation when it may not be possible to assess compliance with either treatment (splinting, endodontic therapy, radiographs and possible extraction) or future regular attendance and in the absence of a randomised controlled trial it is difficult to justify for no proven functional benefit. ${ }^{1}$

This conclusion was not based solely on the untoward outcome described in the current case report but is in accordance with recommendations from those clinically experienced, such as Andreason, ${ }^{5,6}$ Ravn, $^{5-7}$ Sundstrom ${ }^{5}$ and Von Arx ${ }^{8}$ all of whom ultimately advise against primary incisor replantation.

1. Moss S J, Maccaro H. Examination, evaluation and behaviour management following injury to primary incisors. N Y State Dent J 1985: 51: 87-92.

2. Knoshita S, Mitomi T, Taguchi Y, Noda T. Prognosis of replanted primary incisors after injuries. Endod Dent Traumatol 2000; 16: 175-183.

3. American Association of Endodontists. Treatment of the avulsed permanent tooth: recommended guidelines of the American Association of Endodontists. Dent Clin North Am 1995; 39: 221225.

4. Royal College of Surgeons of England. National Clinical Guidelines and Policy Documents 1999. pp 9-14. DPB - Paediatric Dentistry UK 1999.

5. Andreason J O, Sundstrom B, Ravn J J. The effect of traumatic injuries to primary teeth on their permanent successors. I. A clinical and histological study of 117 injured permanent teeth. Scand J Dent Res 1971; 79: 219-283.

6. Andreason J 0, Ravn J J. The effect of traumatic injuries to primary teeth on their permanent successors. Il. A clinical and radiographic follow up study of 213 injured teeth. Scand J Dent Res 1971; 79: 284-294.

7. Ravn J J. Sequelae of acute mechanical trauma in the primary dentition. A clinical study. J Dent Child 1968; 35: 281-289.

8. Von Arx T. Developmental disturbances of permanent teeth following trauma to the primary dentition. Aus Dent J 1993; 38: 1-10.

doi: 10.1038/sj.bdj.4813239

\section{Practising with pacemakers}

Sir, I wonder if I could be permitted to reply to the letter by Dr Balfry $(B D J ; 199$ : 625). I am a practising dentist and had a digital pacemaker fitted two years ago. I have regularly used an ultrasonic scaler in my practice without any problems. My pacemaker advice manual advises that 'dental drills, ultrasonic probes to clean teeth, and dental $\mathrm{x}$-rays do not interfere with your pacemaker' This presumes the pacemaker is used and maintained properly.

R. Firth

Thirsk

doi: $10.1038 /$ sj.bdj.4813240

\section{Praise for ozone}

Sir, I, and all the dentists I have spoken with who work in the 'real world' of general practice, fully support the book review by Dr Hayes on Ozone - The revolution in dentistry. HealOzone has transformed my practice where the results of using ozone are far superior to the alternative injecting, drilling and filling methods.

I have worked as a dentist in public health care in Bardu in Troms, the northern part of Norway, for 14 years. I treat all categories of patients and have incorporated HealOzone into my practice routines for almost three years, using it in every caries case. DIAGNOdent and HealOzone avoid or reduce drilling for all my patients and in each case the goal is prevention instead of extension.

I use ozone for a variety of treatments and have achieved excellent results; in fissure caries in combination with fissure sealants; in phobic children who do not tolerate injections using its analgesic effect to remove about $2 \mathrm{~mm}$ of infected dentine in each step; and in shallow smooth-caries lesions where the caries is arrested without drilling.

In large, open carious lesions in primary teeth I remove the gross outer caries and then use HealOzone leaving the caries lesion open. The patients brush into the cavities and they can be filled after approximately three months when the dentine has become hard and shiny.
Approximal caries in dentine I treat as with fissure caries, leaving approximately $2 \mathrm{~mm}$ of infected dentine on the pulpal wall, then dose HealOzone and restore. Radiographically these lesions remineralise. In the case of replacement fillings I use it as an extra step, saving tissue on the pulpal wall before conventional filling therapy and avoiding many root canal treatments for my patients as a result.

Use of ozone before cementation of crowns and bridges avoids pulpal symptoms; in endodontics it disinfects root canals and internal bleaching using HealOzone is superb.

Having incorporated these techniques safely into my practice I am delighted with the results, as are my patients. It is also much more fun being a dentist working with this wonderful concept and I know I am not alone in thinking this.

\section{Perregaard \\ Bardu, Norway \\ doi: 10.1038/sj.bdj.4813241}

\section{No more infected sockets?}

Sir, for well over three years now, immediately after the majority of adult extractions, I give the patient a single dose of 200mg Metronidazole. A patient returning with a post operative infected socket is now a rarity.

I am in a predominantly NHS practice and my prescribing profile from the DPB indicates that my extraction rate is higher than normal, and my extractions with special difficulty are relatively even higher, as I rarely refer. Despite some very difficult cases, the patient still only receives the one tablet.

The cost to me is negligible - each tablet costs me 7.5p (inc VAT!) and the only side effect for the patient is an alcohol free evening, which generally isn't a problem unless it's a Friday!

I implore my colleagues to do likewise and especially forget about a course of antibiotic therapy post operatively which I believe is an unnecessary use of antibiotics.

\section{P. Williams}

Lowestoft

doi: $10.1038 /$ sj.bdj.4813242

\section{Commercialism in marketing}

Sir, it is with great sadness that during our professional careers, we have watched the growth of commercialism in the marketing of dental services.

It is not that we are against patients being informed of what the profession can offer, where to obtain it and the sort of services offered in a particular practice, it is just that it appears that the 
current manner of promotion is becoming more and more commercial. We were particularly concerned to see in the colour supplement of the Sunday Times on 6 November 2005, dentists allowing their patients' names to be published. Bearing in mind Section 3 in Standards for dental professionals regarding confidentiality, published by the General Dental Council, we sincerely hope that they had the permission of the patients to do so. One wonders what the benefit is of publishing these names other than marketing for the practitioner.

It was also stated by a dentist in that article that anyone can say they are a specialist. That may be the case but the General Dental Council clearly states that only those on our Specialist List can call themselves a specialist, anyone doing so who is not on the Specialist List would be in contravention of the General Dental Council regulations. This seems proper and correct, and as stated by the General Dental Council, it enables patients to identify registered dentists who have met certain requirements and been given the right by us to call themselves a specialist.

The question that we put to the profession for debate is: "Are the current methods of marketing dentistry by dentists beneficial to patients and do they enhance the reputation of the profession in the public's eye?'

M. Atkinson, R. Bevan, S. Becker, L. Breitz, P. Brennan, J. Crisp, C. Etherton, R. Ellis, K. Feran, E. Frazer, P. Freiburger, K. Garber, M. Geekie, E. Giedrys-Leeper, L. Greenwall, B. Grundy, M. Heffernan, I. Hetherington, G. Hill, A. Kidd, D. Moxham, N. Olesen, T. Paolella, S. Roland, N. Safdar, K. Stalker, P. Starrs, C. Stephanakis, R. Tant, B. Tibbott, D. Tipton, J. Wade, R. Wadhawani, M. Wise, R. Wozniak

doi: 10.1038/sj.bdj.4813243

\section{Bring back compassion}

Sir, I refer to a recent letter from M. Storey on this subject (BDJ 2005; 199: 695). How times have changed and not for the better. My father in the 1930s and later I, in the late 1950s, were trained to believe that relief of pain was and is the primary objective of any health professional. To this end we were available at all hours of the day and night to treat any patients, registered or not, as their pain required. As recently as five years ago I saw patients at midnight or later as their need arose. Very few abused this. Now we need an algorithm, a primary care trust, a general practitioner and Uncle Tom Cobbley to even decide if treatment is necessary let alone do it. In retirement all I can do is feel sorry for the low level of emergency cover now provided. A decent call out fee and some compassion can bring immense goodwill, lasting years, as well as doing what we are primarily trained for. Bring back compassion for those in pain please. Or is A\&tE to go down the same sorry path?

\section{A. Carmichael}

Preston

doi: $10.1038 /$ sj.bdj.4813245

\section{Edinburgh degrees}

Sir, Stanley Gelbier's series has been very interesting. In his section on 'Degrees in Scotland', he gives a good account of this, with some very recent developments reported. However, it is worth pointing out that Edinburgh University started awarding a higher dental degree in 1966, when the first Doctors of Dental Surgery received their degrees. There has been a small but steady flow since, with a total of about 30 having been awarded. The University of Edinburgh was the first Scottish university to award a higher degree (as opposed to a diploma) and, as far as I am aware, also the first UK university to do so.

Y. Maidment

By email

doi: $10.1038 /$ sj.bdj.4813246

\section{No honours for dentists}

Sir, I have decided to apply for medicine with the purpose of following a career in oral and maxillofacial surgery.

As part of the process I spent time researching which universities welcome applications from dentists. The responses were varied. Most institutions were welcoming and understanding and accept dentists on to graduate entry courses. However an admissions tutor for one of the Cambridge University colleges informed me that: 'Dentistry degrees do not have honours status and are unclassified and therefore ineligible.'

They require the equivalent of a 2.1 science honours degree, which apparently a BDS is not. I graduated from GKT where we did not receive honours but gained a distinction for the separate sections of final examinations.

This seems to me a great shame that Cambridge are ruling out applications from dentists. This also leads me to conclude that they have no interest in training any oral medicine or maxillofacial consultants of the future.

\section{Westcott}

By email

doi: 10.1038/sj.bdj.4813247 